\title{
Health Behavior and Academic Achievement Among Adolescents: The Relative Contribution of Dietary Habits, Physical Activity, Body Mass Index, and Self-Esteem
}

\author{
Álfgeir Logi Kristjánsson, MS \\ Inga Dóra Sigfúsdóttir, $\mathrm{PhD}$ \\ John P. Allegrante, $\mathrm{PhD}$
}

\begin{abstract}
This study tested a structural equation model to estimate the relationship between health behaviors, body mass index (BMI), and self-esteem and the academic achievement of adolescents. The authors analyzed survey data from the 2000 study of Youth in Iceland, a population-based, cross-sectional sample of 6,346 adolescents in Iceland. The model demonstrated good fit with chi-square of $2685(n=5,810, d f=180), p<.001$, Comparative Fit Index value of .94, and a root mean square error of approximation of .049. Lower BMI, physical activity, and good dietary habits were all associated with higher academic achievement; however, health behavior was positively and robustly associated with greater self-esteem. Self-esteem was positively influenced both through physical activity $(\beta=.16)$ and the consumption of fruits and vegetables $(\beta=.14)$. In contrast, poor dietary habits negatively influenced self-esteem and academic achievement, and self-esteem was negatively influenced by increasing levels of BMI $(\beta=-.05)$.
\end{abstract}

Keywords: academic achievement; adolescence; body mass index; health behavior; self-esteem

The health status of children and adolescents, and the potential impact of health behaviors on their academic achievement, is of growing interest to social scientists, public health authorities, and educational policy makers. Prior research has largely sought to identify correlational evidence in support of a positive relationship between good health status, good health habits, and good academic performance. Although there is some

Álfgeir Logi Kristjánsson and Inga Dóra Sigfúsdóttir, Icelandic Centre for Social Research and Analysis, School of Health and Education, Reykjavik University, Iceland. John P. Allegrante, Department of Health and Behavior Studies, Teachers College, and Department of Sociomedical Sciences, Mailman School of Public Health, Columbia University, New York.

Address reprint requests to John P. Allegrante, $\mathrm{PhD}$, Department of Health and Behavior Studies, Teachers College, 525 West 120th Street, New York, NY 10027; phone: (212) 678-3960; fax: (212) 6788259; e-mail: jpa1@columbia.edu.

This work was partially supported by grants from the Icelandic Alcohol and Drug Prevention Committee, the Icelandic Red Cross, the City of Reykjavik, and the Sports and Recreational Committee of Reykjavik to the Icelandic Centre for Social Research and Analysis, and by Fulbright Senior Specialist (2005) and Fulbright Scholar (2007) awards to Dr. Allegrante.

Health Education \& Behavior Vol. XX (X) - xx- $\mathrm{xx}$ DOI: $10.1177 / 1090198107313481$ C 2008 by SOPHE 
evidence for the hypothesized relationship between positive health status, positive health behavior, and academic performance, the findings have been neither robust nor consistent.

The relationship of health behaviors to academic achievement can be confounded by a complex nexus of variables. These include characteristics of school-age children, their families, and schools and a wide range of other unobserved individual psychological and social variables (Ivanovic et al., 2004). Thus, the precise pathways by which health behaviors and other potential exogenous factors influence academic achievement have yet to be illuminated in a coherent theoretical model.

The purpose of this study was to expand on previous work by constructing and testing a structural model of the relationship of health behaviors, body mass index (BMI), and self-esteem to academic achievement. Our selection of variables and the causal ordering we tested in our model was inspired both by the existing literature demonstrating correlations between health behavior and academic achievement and by Bandura's (1977) social learning theory and Rosenberg's (1965) concept of adolescent self-esteem. Thus, the analysis we report in this article was designed to address three specific questions: Does health behavior autonomously influence both self-esteem and academic achievement simultaneously? Does self-esteem mediate the relationship between health behavior and academic achievement? Does greater self-esteem have an independent relationship with higher levels of academic achievement when controlling for other variables?

\section{HEALTH BEHAVIOR AND ACADEMIC ACHIEVEMENT}

Numerous studies conducted in the United States and other countries have attempted to link several health status and health-related behavioral variables to various measures of academic achievement, performance assessments of learning and cognition, and other educational and social outcomes. Most of the studies have focused on the relationship of weight status (or BMI) and physical fitness to academic achievement.

\section{Weight Status and BMI}

Children and adolescents who are overweight or obese appear to do poorly in school (Taras \& Potts-Datema, 2005). In one of the first studies of weight status and school performance, the proportion of obese, Black, inner-city school children requiring special or remedial education was twice that for children who were not obese (Tershakovec, Weller, \& Gallagher, 1994). Similarly, Falkner et al. (2001) reported that both obese girls and boys were significantly more likely to report being held back a grade and more likely to consider themselves poor students than their average-weight counterparts. In a more recent study of more than 7,000 U.S. elementary school students, Datar and Sturm (2006) found that as children became overweight between kindergarten and the end of third grade there were significant reductions in test scores among girls. A study of the relationship between weight status and academic achievement among Icelandic adolescent men and women yielded similar findings (Sigfúsdóttir, Kristjánsson, \& Allegrante, 2007).

\section{Physical Activity}

In light of the evidence on weight status and academic achievement, together with a burgeoning epidemic of overweight children and adolescents in the United States, increasingly more research has focused attention on the relationship between academic 
achievement and physical activity. For example, Sallis et al. (1999) have reported that physical education may have favorable effects on student academic achievement. In one of the largest and most compelling studies to demonstrate a relationship between academic achievement and physical activity, the California Department of Education (2005) examined several thousand students in the fifth, seventh, and ninth grades whose fitness levels were correlated with academic performance on math and reading tests. Students in the study who achieved the minimum required fitness levels on three tests of physical fitness posted higher scores on math and reading tests than those who were less physically fit.

Although most studies of the relationship of health status and health behaviors to academic achievement have found some evidence for the negative impact of being overweight, there is slightly more mixed evidence regarding the relationship between academic achievement and physical fitness. Moreover, almost all studies have consistently shown that socioeconomic status (SES) and proxy measures of SES are powerful correlates of academic achievement that frequently overwhelm the contribution of all other variables. These findings appear to be consistent across cultures and different systems of schooling found in the United States and other countries. Moreover, unlike physical health indicators, the nature of the link between psychological factors-such as self-esteem - and academic achievement has not been established, with no reports of studies that have examined the role of self-esteem as a potential mediator of the relationship between health behaviors and academic achievement in a multivariate analytic context. Finally, and perhaps most important, the literature offers little theoretical guidance with which to organize our thinking about the relationship of health behaviors to academic achievement and does not provide a clear understanding of the mechanisms through which health behaviors may influence academic achievement. Thus, it is difficult to interpret how or why the relationships might exist or how best they can be exploited from a policy perspective.

\section{THE ROLE OF SELF-ESTEEM}

One important factor that potentially mediates the relationship of health behaviors to academic achievement is self-esteem, the individual's appraisal of his or her own selfworth (Harter, 1999). Research on adolescent psychological and social development demonstrates that self-esteem plays a vital role in the well-being of young people by mediating the relations between stress and psychological adjustment (Haine, Ayers, Sandler, Wolchik, \& Weyer, 2003) as well as through personal control beliefs (Flammer, 1995).

High self-esteem seems to confer many positive benefits. For example, high selfesteem has been shown to contribute to behavioral resilience (Dumont \& Provost, 1999) and increased capacity to manage behavioral problems and interpersonal relationships (Harper \& Marshall, 1991). In addition to these benefits, El-Anzi (2005) found a significant positive correlation between academic achievement and both optimism and self-esteem; negative affective states of anxiety and pessimism were negatively correlated. In contrast, low self-esteem has been associated with obesity (French, Story, \& Perry, 1995), unhappiness with one's weight status (Fisher, Schneider, Pegler, \& Napolitano, 1991), and depression (Salmon, James, \& Smith, 1998).

Despite its potential impact as an important mediating influence, self-esteem has received little attention in studies of health and academic achievement among adolescents. Torres, Fernandez, and Maceira (1995) studied adolescents to determine whether 
self-esteem was related to health behaviors and found that it was significantly correlated with certain dimensions of health behavior. In a study of preadolescent children's health behavior, self-esteem, and academic achievement, Tremblay, Inman, and Willms (2000) found that the relationship between physical activity and academic achievement was weak but that participation in physical activity was positively related to higher levels of self-esteem. Similar findings regarding the association between health behavior and high levels of self-esteem have been reported by other investigators (e.g., Huntsinger \& Luecken, 2004).

\section{METHODS}

\section{Sample and Procedures}

The data for this study came from the 2000 Icelandic study, Youth in Iceland. This sample includes students ages 14 and 15 years who were enrolled in the 9th and 10th grades in all Icelandic secondary schools during March 2000. The study respondents represent approximately $82 \%$ of the national population of Iceland in these age groups.

All aspects of data collection were supervised by the Icelandic Centre for Social Research and Analysis at Reykjavik University. The Centre distributed anonymous questionnaires and envelopes for returning completed questionnaires to all secondary schools in Iceland. Teachers at individual school sites supervised the participation of the students in the study and administered the survey questionnaire. All students who attended school on the day that the questionnaire was scheduled to be administered completed the questionnaire. Students were instructed not to write their names, social security numbers, or any other identifying information anywhere on the questionnaire. Once students had completed the questionnaires, they were asked to place their completed questionnaire in the envelope and seal it before returning the questionnaire to the supervising teacher. A total of 6,346 students ( $51.4 \%$ girls, $48.6 \%$ boys) completed the questionnaire.

BMI, a key independent variable in the study, needed to be calculated from selfreports of height and weight. Those students that had not answered the questions on height and weight or who answered them incorrectly or without foundation were screened from the initial sample. This meant that those who reported being either $30 \mathrm{~kg}$ or less in weight or $145 \mathrm{~kg}$ or more in weight were omitted from the sample; similarly, those who reported to be $130 \mathrm{~cm}$ in height or less or $230 \mathrm{~cm}$ in height or more also were omitted. This left a final remaining sample of 5,810 respondents $(51.7 \%$ girls, $48.3 \%$ boys), which constituted approximately $78 \%$ of all 14 - and 15 -year-old students who were enrolled in schools throughout Iceland during the time of the survey on whom complete data were collected and analyzed for this study. Thus, of the 536 cases omitted from the analysis, 307 were omitted due to the failure of students to answer either question about height and weight and the remaining 229 were omitted due to screening.

\section{Measures}

Six latent variables were specified and used in the analysis, along with four observed variables. All latent constructs were measured with multiple indicators. Four additional variables were used as control variables in the study: gender; parental education (a proxy measure of family SES); family structure, that is, whether adolescents lived 
with both biological parents or in other arrangements; and school absenteeism. Approximately $94 \%$ of the estimated 300,000 inhabitants of Iceland are of Norse-Celtic decent and $87 \%$ of the population belongs to the Lutheran State Church (Hagstofa Íslands, 2001). Because of this homogeneity, other exogenous variables, such as race, ethnicity, and religion, which are often used in research in the United States and other countries, were not included in this analysis.

The psychometric properties of all of the items used in our analysis had been previously established as valid and reliable for the Youth in Iceland study. Both translation and criterion-related validity methods were used to establish construct validity for all measures. Internal consistency reliability of the items used in this analysis was generally high, with Cronbach's alpha ranging from .67 to .80 .

Academic Achievement. Academic achievement was the main dependent variable in this study. To estimate the level of academic achievement, respondents were asked to self-report their average grades in the core academic subjects of Icelandic, mathematics, English, and Danish or, alternatively, Swedish or Norwegian. These are subjects that every student in the 9 th and 10th grades in Iceland must complete satisfactorily to complete secondary school. The grade range in Iceland in these subjects is 0 to 10 , with a score of less than 5 resulting in a fail grade and more than 5 resulting in a pass grade. The response format was $0=$ under $4,1=$ about $4,2=$ about $5,3=$ about $6,4=$ about $7,5=$ about $8,6=$ about 9 , and $7=$ about 10 .

$B M I$. BMI was measured by asking respondents to self-report their weight and height. BMI was calculated using the following formula: weight in kilograms/(height in meters $\times$ height in meters).

Poor Dietary Habits. To measure if respondents consumed a poor diet, we constructed the variable labeled "bad diet." This was done by asking respondents to selfreport how often they ate (1) potato chips, (2) French fries, or (3) a hamburger or a hot $\operatorname{dog}$. The response format was $1=$ almost never, $2=$ less than once a week, $3=$ every week, $4=$ once a day, and $5=$ more than once a day.

Consumption of Fruits and Vegetables. To measure if respondents had positive dietary habits, we constructed the variable labeled "fruits and vegetables." This was done by asking respondents to self-report how often they ate either fruits or vegetables or both. The response format was $1=$ almost never, $2=$ less than once a week, $3=$ every week, 4 = once a day, and $5=$ more than once a day.

Physical Activity. Physical education is compulsory in the Icelandic national secondary school curriculum and students usually participate in one lesson per week. Thus, to measure additional physical activity, respondents were asked two questions, which were intended to measure different levels of physical activity beyond the one compulsory school session: "How often do you participate in sports with a sports club or a team," which captures those who attend formal training and/or practicing with such agents, and "How often do you physically test yourself so you wind yourself significantly or sweat," which is a more general question on physical activity. The response format was 1 =almost never, 2 = less than once a week, $3=$ once a week, 4=2-3 times a week, $5=4-5$ times $a$ week, and $6=$ almost every day. 
Self-Esteem. Self-esteem was measured with five items from the Rosenberg SelfEsteem Scale (Rosenberg, 1965). We restricted our use to five items from the standard 10 -item scale because of the fit indices and factor loadings we generated in the overall structural model. The items we used as a measure of self-esteem included the following: "On the whole, I am satisfied with myself"; "I feel that I have a number of good qualities"; "I am able to do things as well as most other people"; "I feel that I'm a person of worth, at least on an equal plane with others"; and "I take a positive attitude toward myself." The response format was $0=$ strongly disagree, $1=$ disagree, $2=$ agree, and 3 = strongly agree. Hagborg (1993) conducted a study of concurrent validity of the Rosenberg Self-Esteem Scale and the Harter Self-Perception Profile for Adolescents and found positive evidence of convergent validity in the construct.

Control Variables. Studies (e.g., Dumais, 2002) have shown that gender, level of parental education as a proxy measure of SES, family structure, and school absenteeism comprise variables that should be considered when studying the relationship of health behaviors and academic achievement. Hence, we treated the following four variables as control variables in the analysis: gender was a dichotomized variable, with $0=$ boys and 1 = girls. Parental education was obtained by asking students separate questions about their fathers' and mothers' educational attainment. The response format was $1=$ finished elementary school or less, $2=$ started a school on the secondary level, $3=$ finished secondary level, $4=$ started university level, and $5=$ has a university degree. Family structure was measured by asking, "Who lives with you in your home?" The response format was $1=$ both parents, $2=$ mother and not father, $3=$ father and not mother, $4=$ mother and partner, $5=$ father and partner, $6=$ I live on my own, and $7=$ other arrangement. This variable was then collapsed and dichotomized with $0=$ lives with both parents $(73 \%)$ and $1=$ other arrangements $(27 \%)$. School absenteeism was obtained by asking students to self-report how frequently they skipped classes. The response format was $1=$ almost never, 2 = less than once a month, $3=$ every month, $4=$ every week, and $5=$ almost daily.

\section{Measurement Model and Data Analysis}

Our analysis sought to answer three specific questions: (1) Are the health behavior variables directly related to academic achievement when controlling for the possibly confounding impact of self-esteem and the background variables? (2) Does self-esteem play a mediating role on the influences of health behavior on academic achievement? and (3) Does greater self-esteem have an independent relationship with higher levels of academic achievement when controlling for other variables in the model? Our analysis was based on structural equation modeling (SEM) and was conducted using AMOS (Arbuckle \& Wothke, 1999; Maruyama, 1998). SEM allowed us to explicitly model both direct and indirect effects using both measured and latent variables.

Most social-psychological concepts are abstract and cannot be measured directly, thus modeling entails specifying the underlying theoretical concepts and their operationalized measurement. The first step in testing the structural model was to specify and test the measurement model. A measurement model specifies the structural relationship between the underlying latent constructs and their observed measures (Bollen, 1989). We specified six latent constructs in the analysis: parental education, bad food, consumption of fruits and vegetables, physical activity, self-esteem, and academic achievement. The specification included the number of factors, the number of indicators for each factor, and whether the measurement errors are allowed to correlate. Confirmatory 
factor analysis was used to test the fit of the hypothesized factor structure to the covariance matrix of the observed variables. In the construction of all latent variables, we used confirmatory factor analysis from the beginning because the latent variables already made clear what indicators we should be seeking.

The structural equation model we tested can be expressed as the following equation:

$$
\eta=\beta \eta+\Gamma \xi+\zeta
$$

where $\beta$ is the matrix of regression weights interrelating the endogenous $(\eta)$ variable, school achievement, as well as the mediating variables bad food, fruits and vegetables, physical activity, BMI, and self-esteem. $\Gamma$ is the matrix of regression weights relating the exogenous $(\xi)$ variables, gender, parental education, family structure, and school absenteeism, to the endogenous $(\eta)$ ones and $\zeta$ is a vector of error terms.

The traditional method of constructing structural equation models calls for performing a chi-square test of the null hypothesis that the observed and the expected matrices are identical. The model is accepted if the test fails to reject the null hypothesis. However, in large samples, such tests can lead to the rejection of good models on the basis of trivial misspecifications (Gerbing \& Anderson, 1993). Hence, we used a combination of goodness-of-fit indices to assess fit of the model to the data. There are a number of goodness-of-fit indices that are calculated by the AMOS program, each of which has various strengths and weaknesses and evaluates fit in different ways. Prior work by McDonald and Ho (2002) suggested that two of these indices, the Comparative Fit Index (CFI) and root mean square error of approximation (RMSEA), along with the chi-square statistic, would constitute appropriate measures for examining the fit of the proposed theoretical model. Models are considered a good fit if the CFI is greater than .90 and the RMSEA, a measure of lack of fit of the model to the population covariance matrix per degree of freedom for the model, is less than .05 .

\section{RESULTS}

Respondents included an approximately equal number of men and women who had parents who had completed at least a secondary school education and who, for the most part, lived with both parents. School absenteeism in our sample was fairly low and selfesteem was generally high. With respect to academic achievement, most of the respondents reported grades of 7 or higher in the four school subjects that, when combined, constituted our measure of academic achievement $(M=16.60, S D=5.73)$. Respondents also reported on average that they were physically active 4 to 5 times a week, with a mean of $5.01(S D=3.01)$ for the combined physical activity measures. The mean scores for the two questions that comprised our composite measure of healthy diet, that is, consumption of fruits and vegetables and bad food, were $3.64(S D=1.74)$ and 7.07 (SD $=2.58$ ), respectively. The average weight for the participants in the study was $61.37 \mathrm{~kg}$ $(S D=11.88)$ and the average height was $170.43 \mathrm{~cm}(S D=8.50)$; average BMI was $21.05(S D=3.33)$. Factor loadings were robust and ranged from .66 (How often do you eat potato chips and bad food?) to .86 (grades in Icelandic and school achievement), with all of the factor loadings being statistically significant $(p<.01)$.

Table 1 presents the zero-order correlation matrix for the analysis of variables. As shown, the mediating variables, bad food, fruits and vegetables, BMI, physical activity, and self-esteem, were all significantly correlated with one another, except for bad food 


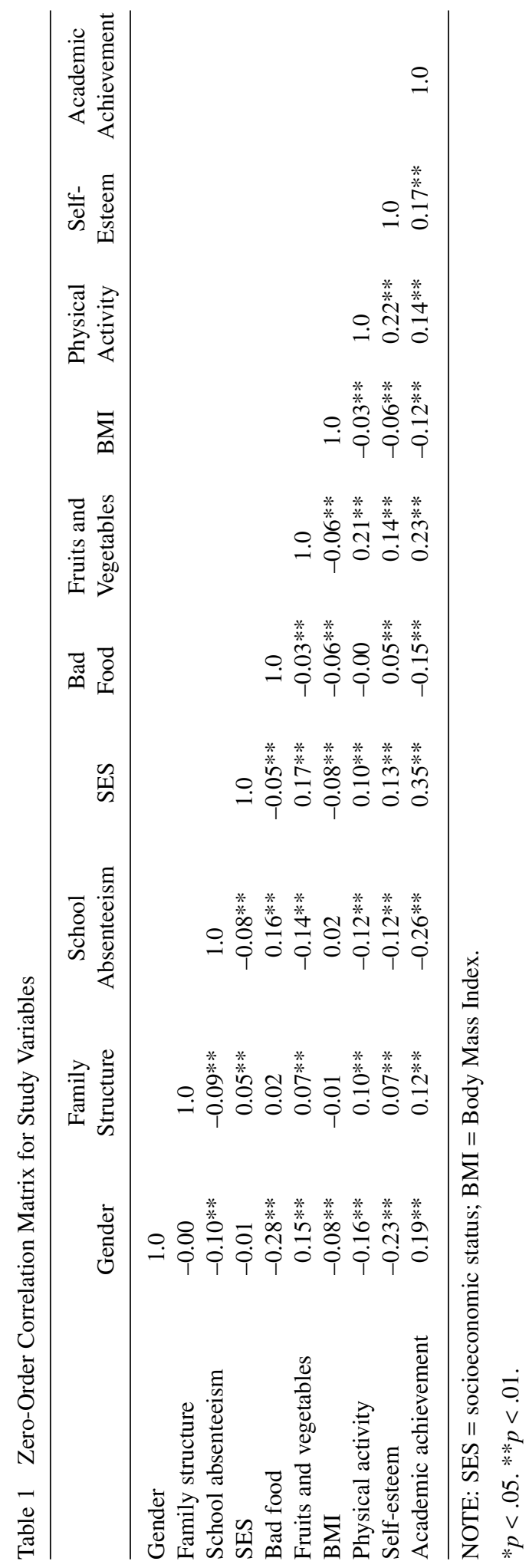


and physical activity. (This underlines the importance of controlling for each of the items when estimating the effects of the others.) The data also show that consuming bad food was negatively correlated with academic achievement $(r=-.15)$, whereas more consumption of fruits and vegetables was positively and strongly correlated with academic achievement $(r=.23)$. As was expected, increasing BMI was negatively correlated with academic achievement $(r=-.12)$ and increased physical activity was positively correlated with academic achievement $(r=.14)$. Moreover, self-esteem was positively correlated with academic achievement $(r=.17)$. Finally, the correlation matrix also shows that the health behavior variables were significantly related to self-esteem. Consuming bad food was positively correlated with self-esteem $(r=.05)$, but only to a very small extent, whereas consuming fruits and vegetables was moderately related to self-esteem $(r=.14)$. On the other hand, BMI had a small yet negative correlation with self-esteem $(r=-.06)$ but physical activity was rather strongly related to self-esteem $(r=.22)$.

To identify whether the health behavior variables influenced academic achievement when controlling for the possibly confounding impact of the background variables, as well as the mutual effect they might exert on academic achievement or one another, we tested the structural model shown in Figure 1. As can be seen, the results shown indicate that the model met the CFI and RMSEA criteria for fit. The final model had a CFI value of .94 and a RMSEA of .049, which implies that the proposed model fits the data well. Because we analyzed data from a large sample $(n=5,810)$, the chi-square tests were significant $(p<.05)$. Fit indices other than the chi-square test revealed that the model fits the data well.

In the context of the hypothesized relationships of our model, the standardized $(\beta)$ and unstandardized regression weights from the structural equation model are shown in Table 2. When the direct and indirect effects that health behavior had on academic achievement are examined, it can be seen that physical activity is directly and positively related to academic achievement $(\beta=.08, t>1.96)$, but to a lesser extent indirectly related to achievement $(\beta=.02, t>1.96)$ through self-esteem. In contrast, bad food had a negative direct relationship with academic achievement $(\beta=-.09, t>1.96)$, but bad food had no indirect relationship with achievement through self-esteem. Consuming fruits and vegetables had a direct positive relationship with academic achievement $(\beta=$ $.08, t>1.96$ ) but a very small indirect relationship with academic achievement through self-esteem $(\beta=.02, t>1.96)$. Higher levels of BMI were directly and negatively related to academic achievement $(\beta=-.06, t>1.96)$ but increased BMI had no indirect relationship with achievement through self-esteem. Self-esteem had a strong and positive direct (nonmediated) relationship with academic achievement $(\beta=.12, t>1.96)$. On the other hand, physical activity had a strong, direct relationship with self-esteem ( $\beta=.16, t>1.96)$, as did consumption of fruits and vegetables $(\beta=.14, t>1.96)$. Finally, increasing BMI had a negative relationship with self-esteem $(\beta=-.05, t>1.96)$ but consuming bad food had no relationship with self-esteem $(\beta=.00, t<1.96)$.

\section{DISCUSSION}

This investigation sought to extend previous work by estimating the relationship of BMI, health behaviors, and self-esteem to academic achievement among adolescents in an effort to better understand the role and impact of these variables in a multivariate model. We used a large data set of more than 5,000 adolescent respondents-virtually the entire national Icelandic population of students in the age range we studied-and both the response rate and quality and completeness of our data were high. 
Table 2 Standardized and Unstandardized Regression Weights for the Final Model With Self-Esteem as Mediating Factor

\begin{tabular}{|c|c|c|c|c|}
\hline ModelRelationship & $\begin{array}{l}\text { Standardized } \\
\text { Coefficients }\end{array}$ & $\begin{array}{l}\text { Unstandardized } \\
\text { Coefficients }\end{array}$ & SE & $\mathrm{CR}$ \\
\hline \multicolumn{5}{|l|}{ Hypothesized } \\
\hline Bad food $\rightarrow$ academic achievement & $-.09 * *$ & -.26 & .048 & -5.473 \\
\hline $\begin{array}{l}\text { Fruits and vegetables } \rightarrow \\
\text { academic achievement }\end{array}$ & $.08 * *$ & .17 & .037 & 4.544 \\
\hline $\mathrm{BMI} \rightarrow$ academic achievement & $-.06 * *$ & -.03 & .006 & -4.593 \\
\hline Physical activity $\rightarrow$ self-esteem & $.16^{* *}$ & .07 & .007 & 9.000 \\
\hline Bad food $\rightarrow$ self-esteem & .00 & .00 & .019 & 0.153 \\
\hline Fruits and vegetables $\rightarrow$ self-esteem & $.14^{* *}$ & .12 & .015 & 7.828 \\
\hline BMI $\rightarrow$ self-esteem & $-.05^{* *}$ & -.01 & .002 & -3.909 \\
\hline $\begin{array}{l}\text { Self-esteem } \rightarrow \text { academic } \\
\text { achievement }\end{array}$ & $.12 * *$ & .32 & .040 & 7.959 \\
\hline \multicolumn{5}{|l|}{ Control } \\
\hline Gender $\rightarrow$ physical activity & $-.21 * *$ & -.57 & .045 & -12.646 \\
\hline Gender $\rightarrow$ bad food & $-.30^{* *}$ & -.28 & .014 & -19.706 \\
\hline Gender $\rightarrow$ fruits and vegetables & $.17 * *$ & .23 & .022 & 10.408 \\
\hline Gender $\rightarrow$ BMI & $-.08 * *$ & -.56 & .087 & -6.409 \\
\hline Gender $\rightarrow$ self-esteem & $-.26 * *$ & -.28 & .016 & -17.107 \\
\hline Gender $\rightarrow$ academic achievement & $.24 * *$ & .69 & .042 & 16.402 \\
\hline Family structure $\rightarrow$ physical activity & $.09 * *$ & .28 & .048 & 5.869 \\
\hline Family structure $\rightarrow$ bad food & $.03 *$ & .03 & .015 & 2.250 \\
\hline $\begin{array}{l}\text { Family structure } \rightarrow \text { fruits and } \\
\text { vegetables }\end{array}$ & $.06 * *$ & .090 & .024 & 3.743 \\
\hline Family structure $\rightarrow$ BMI & -.00 & -.01 & .098 & -0.140 \\
\hline Family structure $\rightarrow$ self-esteem & $.03 *$ & .04 & .016 & 2.253 \\
\hline $\begin{array}{l}\text { Family structure } \rightarrow \text { academic } \\
\text { achievement }\end{array}$ & $.08 * *$ & .27 & .041 & 6.733 \\
\hline $\begin{array}{l}\text { Parental education } \rightarrow \\
\text { physical activity }\end{array}$ & $.17 * *$ & .22 & .028 & 7.785 \\
\hline Parental education $\rightarrow$ bad food & $-.04 *$ & -.02 & .009 & -2.310 \\
\hline $\begin{array}{l}\text { Parental education } \rightarrow \text { fruits and } \\
\text { vegetables }\end{array}$ & $.27 * *$ & .19 & .016 & 11.669 \\
\hline Parental education $\rightarrow$ BMI & $-.10^{* *}$ & -.32 & .057 & -5.528 \\
\hline Parental education $\rightarrow$ self-esteem & $.09 * *$ & .05 & .011 & 4.397 \\
\hline $\begin{array}{l}\text { Parental education } \rightarrow \text { academic } \\
\text { achievement }\end{array}$ & $.38 * *$ & .54 & .031 & 17.490 \\
\hline $\begin{array}{l}\text { School absenteeism } \rightarrow \\
\text { physical activity }\end{array}$ & $-.15^{* *}$ & -.23 & .024 & -9.361 \\
\hline School absenteeism $\rightarrow$ bad food & $.14 * *$ & .07 & .008 & 9.896 \\
\hline $\begin{array}{l}\text { School absenteeism } \rightarrow \text { fruits and } \\
\text { vegetables }\end{array}$ & $-.13^{* *}$ & -.10 & .012 & -8.359 \\
\hline School absenteeism $\rightarrow$ BMI & .00 & .01 & .049 & 0.206 \\
\hline School absenteeism $\rightarrow$ self-esteem & $-.09 * *$ & -.05 & .008 & -6.221 \\
\hline $\begin{array}{l}\text { School absenteeism } \rightarrow \text { school } \\
\text { achievement }\end{array}$ & $-.19 * *$ & -.30 & .021 & -14.051 \\
\hline
\end{tabular}

NOTE: $\mathrm{CR}=$ censored regression; $\mathrm{BMI}=$ Body Mass Index.

$* p<.05 . * * p<.01$. 


\section{Control Variables}

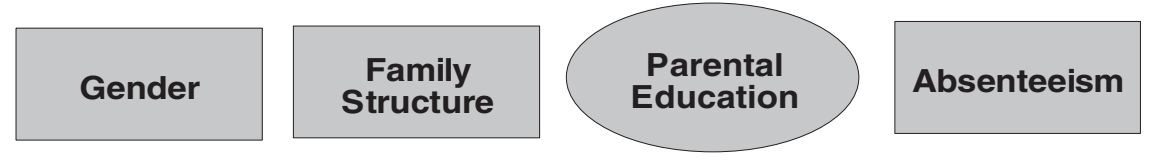

\section{Independent \\ Variables}

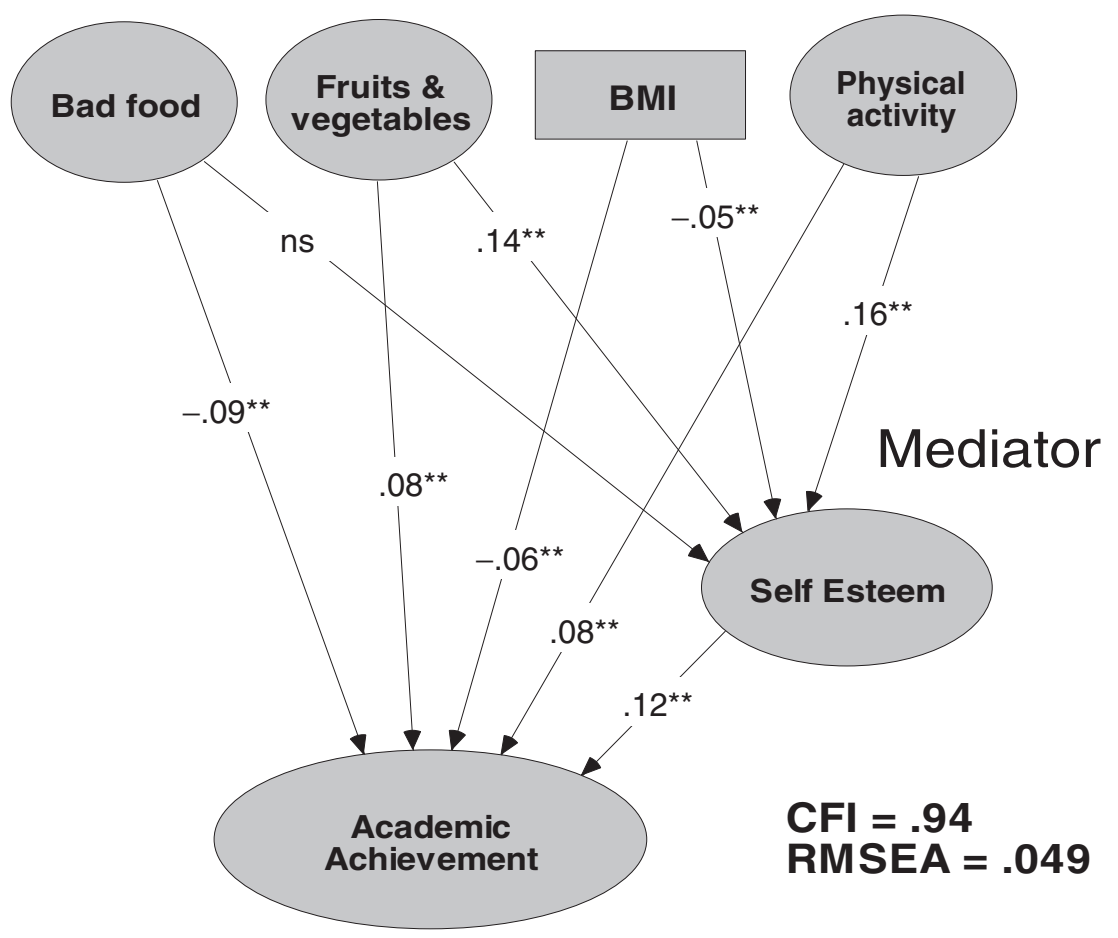

Figure 1 Relationship between BMI, health behaviors, and self-esteem and academic achievement. NOTE: For purposes of clarity, the path lines from the control variables to all of the other variables are implied but not drawn.

$* * p<.01$.

Consistent with most of the previous research, our structural equation model showed that nonoverweight status, as measured by BMI, participation in physical activity, and good dietary habits, was associated with higher academic achievement. However, our findings also show that health behavior was positively and robustly associated with greater self-esteem. Self-esteem was positively influenced both through physical activity $(\beta=.16)$ and the consumption of fruits and vegetables $(\beta=.14)$. In contrast, 
we found that poor dietary habits negatively influenced self-esteem and academic achievement and, consistent with previous reports, that self-esteem was negatively influenced by increasing levels of BMI $(\beta=-.05)$. Although our data show that selfesteem was positively related to academic achievement, it is noteworthy that it was a weak mediator of the relationship between health behaviors and academic achievement. Notwithstanding, health behavior did autonomously influence and was positively related to self-esteem and academic achievement as well as higher levels of self-esteem in our sample.

The interpretation of these results should be considered in light of several methodologic limitations. First, similar to most previous studies that have examined the relationship of health behavior to academic achievement, we used cross-sectional data. We also studied a comparatively homogeneous group of adolescents whose unique cultural and school experiences limit generalization of our findings to other populations. Second, although our measures were valid and reliable, the data we collected came from selfreports of behavior from adolescents, where the possibility of response error should be considered. For example, women are more likely than men to underreport their weights by an average of 1 to $2 \mathrm{~kg}$, and underreporting is more common among heavier respondents (Spencer, Appleby, Davey, \& Key, 2002). However, because this was not a genderspecific study, we do not believe this was a problem, other than that stronger relationships might have been discovered between BMI and self-esteem and academic achievement. Third, because our measure of academic achievement was based on student self-estimates of their grades, it is possible that students may have overestimated their academic performance. However, previous work (Schiller, 2002) suggests that such self-reports of academic performance among high school students are plausible because they compare favorably when checked for correspondence against individual transcript-based data.

Despite these limitations, the fact that self-esteem did not, for the most part, mediate the impact of the health-behavior variables on academic achievement supports the notion that adolescent engagement in healthy behavior remains important if societies wish to simultaneously improve both the health status and academic-achievement goals of young people. The fact that health behavior also strongly influences self-esteem only reinforces the significance of this fact. Furthermore, the influence that health behaviors have on academic achievement appears mostly to take place outside the impact of self-esteem.

Finally, from a theoretical and methodological perspective, our findings may only serve to underscore the complexity of the relationship between physical and mental health and academic achievement and the formidable challenges in studying this relationship. Our understanding of how such variables interact to influence cognitive processes and academic achievement is still incomplete. There may be other important constructs that contribute significantly to explaining academic achievement that have yet to be identified and studied along with other health behaviors. Moreover, such constructs may have differential influence in diverse cultural, economic, and schooling contexts, and more research needs to be done to elucidate the measurement and meaning of such constructs across racially and developmentally diverse population samples. In addition, more attention in future research also should be given to further study of both state and trait personality variables, including affective and emotional states such as anxiety and depression, stressful life events, social support, and other mental-health indicators. Finally, although cross-sectional data have enabled us to model the relationship of health status, health behavior, and self-esteem to academic achievement, further advancement in understanding how academic achievement varies in relation to these and other individual and social factors over time will require cohort designs and prospective study. 


\section{Implications for Practice}

In the context of the emerging debate in the United States and other advanced economies about improving both academic achievement and adolescent health, our findings have several important implications for school policy and practice. First, schools should strengthen the opportunities to facilitate, support, and reinforce a wide range of health-related behavior. This should include creating opportunities to incorporate healthy cafeteria choices that facilitate the consumption of fruits and vegetables and reducing overall intake of animal fat and high-caloric beverages. Second, schools should place more emphasis on adolescent participation in physical activity of an enjoyable, noncompetitive nature to increase the number of minutes of moderate to vigorous physical activity. Third, given the direct and indirect influence of self-esteem on health behaviors and academic achievement, schools would be wise to make additional investments in curriculum and other programmatic efforts to build and support the self-esteem of students.

\section{References}

Arbuckle, J. L., \& Wothke, W. (1999). AMOS 4.0 user's guide. Chicago: Small Waters Corporation.

Bandura, A. (1977). Social learning theory. Englewood Cliffs, NJ: Prentice Hall.

Bollen, K. A. (1989). Structural equations with latent variables. New York: John Wiley.

California Department of Education. (2005). California physical fitness test: A study of the relationship between physical fitness and academic achievement in California using 2004 test results. Sacramento: Author.

Datar, A., \& Sturm, R. (2006). Childhood overweight and elementary school outcomes. International Journal of Obesity, 30, 1449-1460.

Dumais, S. A. (2002). Cultural capital, gender, and school success: The role of habitus. Sociology of Education, 75, 44-68.

Dumont, M., \& Provost, M. A. (1999). Resilience in adolescents: Protective role of social support, coping strategies, self-esteem, and social activities on experience of stress and depression. Journal of Youth and Adolescence, 28, 343-363.

El-Anzi, F. O. (2005). Academic achievement and its relationship with anxiety, self-esteem, optimism, and pessimism in Kuwaiti students. Social Behavior and Personality, 33, 95-104.

Falkner, N. H., Neumark-Sztainer, D., Story, M., Jeffrey, R. W., Beuhring, T., \& Resnick, M. D. (2001). Social, educational, and psychological correlates of weight status in adolescents. Obesity Research, 9, 32-42.

Fisher, M., Schneider, M., Pegler, C., \& Napolitano, B. (1991). Eating attitudes, health-risk behaviors, self-esteem, and anxiety among adolescent families in a suburban high-school. Journal of Adolescent Health, 12, 377-384.

Flammer, A. (1995). Developmental analysis of control beliefs. In A. Bandura (Ed.), Self-efficacy in changing societies (pp. 69-113). Cambridge, UK: Cambridge University Press.

French, S. A., Story, M., \& Perry, C. L. (1995). Self-esteem and obesity in children and adolescents: A literature-review. Obesity Research, 3, 479-490.

Gerbing, D. W., \& Anderson, J. C. (1993). Monte Carlo evaluations of goodness-of-fit indices for structural equation models. In K. A. Bollen \& J. S. Long (Eds.), Testing structural equation models (pp. 40-66). Newbury Park, CA: Sage.

Hagborg, W. J. (1993). The Rosenberg Self-Esteem Scale and Harter Self-Perception Profile for Adolescents: A concurrent validity study. Psychology in the Schools, 30, 132-136.

Hagstofa Íslands [Statistics Iceland]. (2001). Statistical yearbook of Iceland 2001 (Statistics of Iceland III, 82). Reykjavik, Iceland: Author. 
Haine, R. A., Ayers, T. S., Sandler, I. N., Wolchik, S. A., \& Weyer, J. L. (2003). Locus of control and self-esteem as stress-moderators or stress-mediators in parentally bereaved children. Death Studies, 27, 619-640.

Harper, J. F., \& Marshall, E. (1991). Adolescents' problems and their relationship to self-esteem. Adolescence, 26, 799-807.

Harter, S. (1999). The construction of the self: A developmental perspective. New York: Guilford.

Huntsinger, E. T., \& Luecken, L. J. (2004). Attachment relationships and health behavior: The mediational role of self-esteem. Psychology and Health, 19, 515-526.

Ivanovic, D. M., Perez, H. T., Olivares, M. G., Díaz, N. S., Leyton, B. D., \& Ivanovic, R. M. (2004). Scholastic achievement: A multivariate analysis of nutritional, intellectual, socioeconomic, sociocultural, familial, and demographic variables in Chilean school-age children. Nutrition, 20, 878-889.

Maruyama, G. M. (1998). Basics of structural equation modeling. Thousand Oaks, CA: Sage.

McDonald, R. P., \& Ho, M.H.R. (2002). Principles and practice in reporting structural equation analyses. Psychological Methods, 7, 64-82.

Rosenberg, M. (1965). Society and the adolescent self-image. Princeton, NJ: Princeton University Press.

Sallis, J. F., McKenzie, T. L., Kolody, B., Lewis, M., Marshall, S., \& Rosengard, P. (1999). Effects of health-related physical education on academic achievement: Project SPARK. Research Quarterly for Exercise and Sport, 70, 127-134.

Salmon, G., James, A., \& Smith, D. M. (1998). Bullying in schools: Self-report anxiety, depression, and self esteem in secondary school children. British Medical Journal, 317, 924-925.

Schiller, K. S. (2002). Self-report vs. transcript-derived mathematics grades for the first two years of high school: Evidence from the national education longitudinal study of 1998. Unpublished manuscript, Educational Administration and Policy Studies working paper, University at Albany, New York.

Sigfúsdóttir, I. D., Kristjánsson, A. L., \& Allegrante, J. P. (2007). Health behaviour and academic achievement in Icelandic school children. Health Education Research, 22, 70-80.

Spencer, E. A., Appleby, P. N., Davey, G. K., \& Key, T. J. (2002). Validity of self-reported height and weight in 4808 EPIC-Oxford participants. Public Health Nutrition, 5, 561-565.

Taras, H., \& Potts-Datema, W. (2005). Obesity and student performance at school. Journal of School Health, 75, 291-295.

Tershakovec, A. M., Weller, S. C., \& Gallagher, P. R. (1994). Obesity, school performance and behaviour of black, urban elementary school children. International Journal of Obesity and Related Metabolic Disorders, 18, 323-327.

Torres, R., Fernandez, F., \& Maceira, D. (1995). Self-esteem and value of health as correlates of adolescent health behavior. Adolescence, 30, 403-412.

Tremblay, M. S., Inman, J. W., \& Willms, J. D. (2000). The relationship between physical activity, self-esteem, and academic achievement in 12-year-old children. Pediatric Exercise Science, 12, 312-323. 